\title{
Growth and mortality estimates for red sea urchin Strongylocentrotus franciscanus from San Nicolas Island, California
}

\author{
Thomas A. Ebert ${ }^{1}$, Michael P. Russell ${ }^{2}$ \\ ${ }^{1}$ Department of Biology, San Diego State University, San Diego, California 92182-0057, USA \\ ${ }^{2}$ California Academy of Sciences, Golden Gate Park, San Francisco, California 94118-4509, USA
}

\begin{abstract}
The red sea urchin, Strongylocentrotus franciscanus, is one of the larger if not the largest shallow water sea urchin species in the world, with a maximum test diameter $>16 \mathrm{~cm}$. It is a numerically and functionally important element of benthic assemblages along the west coast of North America and is the basis of a commercial fishery. Despite these points, there are very few data on its basic population biology. We studied 2 intertidal populations of $S$. franciscanus from exposed sandstone benches on San Nicolas Island, California, USA, and estimated growth and survival. The shapes of its growth curves were similar to many tropical and temperate species in that ca $42 \%$ of asymptotic size was attained during the first year of growth. Sea urchins at Cosign Cove grew more slowly and attained a smaller maximum size than did those at Northwest Point, so at $10 \mathrm{yr}$ diameters would be 6.7 and $7.9 \mathrm{~cm}$, respectively. Annual mortality rate was about $10 \%$ for both sites. Although growth rates were different at the 2 sites at San Nicolas Island, relative sizes of the demi-pyramids ('jaws') of Aristotle's lantern were the same. Size of demi-pyramids relative to test diameter has been shown to be responsive to food abundance in other sea urchin species, so the different growth rates at the 2 sites either represent responses to environmental factors other than food or relative growth of jaws in $S$ franciscanus is more canalized than in other sea urchin species.
\end{abstract}

\section{INTRODUCTION}

The red sea urchin, Strongylocentrotus franciscanus, is a dominant member of benthic assemblages along the west coast of North America (reviewed by Lawrence 1975, Harrold \& Pearse 1987) and is the basis of a fishery (Kato \& Schroeter 1985, Tegner 1989). Furthermore, maximum size of this species is very large. Low (1975) and Kramer \& Nordin (1975) collected S. franciscanus between 16 and $17 \mathrm{~cm}$, which makes this species one of the larger if not the largest shallow-water sea urchin species in the world and hence of interest with respect to the evolution of the co-evolved traits that require or constrain such large size. Despite its ecological and commercial importance, few data exist on basic population parameters such as growth and mortality.

A small number of growth studies have previously been published for Strongylocentrotus franciscanus.
Leighton (1967) documented growth in the laboratory over a period of 2 mo and collected bimonthly sizefrequency data for 14 mo at 2 sites in southern California (Leighton 1968). Swan (1961) measured the growth of animals held in cages suspended from a dock and Low (1975) and Schroeter (1978) held animals in pens in the field. Baker (1973) and Low (1975) used mark-recapture methods with invasive tags threaded into the test, and Ebert (1977) and Rowley (1990) used mark-recapture with tetracycline. In all of these studies the numbers of observations on which growth can be based is small, sizes are highly restricted or tagging procedures or manipulations compromise results and hence application to natural populations.

There are no studies that have attempted to estimate survival for all sizes of Strongylocentrotus franciscanus. Rowley (1990) estimated survival rates but only for newly settled sea urchins. Information exists on 
possible predators (e.g. Cowen 1983, Tegner \& Levin 1983) but loss rates due to predation were not estimated.

Here we provide estimates of growth and mortality rates for red sea urchins in 2 intertidal pools at San Nicolas Island, California. These initial estimates provide a basis for future comparative work on the lifehistory of this species.

\section{MATERIALS AND METHODS}

San Nicolas Island $\left(33^{\circ} 15^{\prime} \mathrm{N}, 119^{\circ} 30^{\prime} \mathrm{W}\right.$ ) lies ca $100 \mathrm{~km}$ off the coast of southern California (Fig. 1). The United States Navy restricts access to the island and so the nearshore and shallow subtidal communities are left relatively undisturbed. The island is a broad, complexly faulted anticline, consisting of marine sandstone and siltstone beds (Vedder \& Norris 1963). The coastline is a series of dipping sandstone benches interrupted by tidal channels and sandy beaches of varying lengths.

We studied 2 intertidal populations along the northwest tip of the island (Fig. 1). Samples were from 2 large pools that contained both Strongylocentrotus franciscanus and $S$. purpuratus. The northernmost pool, 'Northwest Point', is deeper and somewhat more exposed to the surf than the southern pool, 'Cosign Cove'.

Between 7 and 8 April 1989, we removed, measured, injected with tetracycline, and replaced red sea urchins in the 2 pools: 188 individuals were collected at Cosign Cove but 3 were crushed during collection and so 185 were tagged and returned. At Northwest Point, 151 specimens were collected, none was crushed and so all were tagged and returned. Approximately $1 \mathrm{yr}$ later (21-22 March 1990), we exhaustively searched, collected and processed all the red urchins from both pools, 231 from Cosign Cove and 153 from Northwest

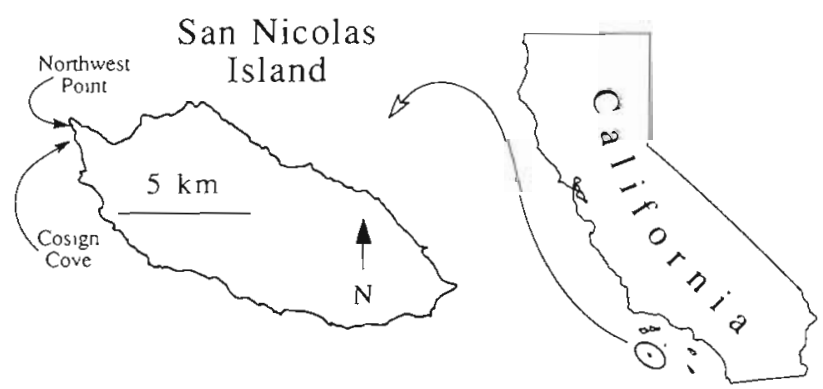

Fig. 1 Sites where 2 intertidal populations of Strongylocentrotus franciscanus were sampled on San Nicolas Island, California. Both the northern site (Northwest Point) and the southern site (Cosign Cave) are on exposed sandstone benches
Point. On both sampling dates we measured maximum test diameter of each animal with vernier calipers. Growth measurements were made based on the tetracycline marks, a method which has been successfully employed to assess growth in a number of other sea urchin species (Ebert 1977, 1980a, b, 1982, Schroeter 1978, Russell 1987, Rowley 1990). Tetracycline binds to calcium ions and becomes incorporated into the skeletal elements that are growing. After the tagged sea urchins are recaptured and the skeletal elements are cleansed of soft tissue using sodium hypochlorite, ultraviolet light reveals the size of the skeletal elements at the time of tagging. Knowledge of original size, final size, and the time interval $(\Delta t)$ are sufficient to estimate parameters of a growth function.

To assess growth, we examined demi- or half pyramids of Aristotle's lantern (the 'jaws') because these skeletal ossicles yield clear tetracycline marks under ultraviolet light without having to grind away a surface layer as required when ossicles of the test are used (Ebert 1977, 1988). By determining the allometric relationship between test and jaw length, we were able to convert the growth parameter estimates for jaws into parameter estimates for test growth (cf. Ebert 1982, Russell 1987). Jaws do not include the teeth so erosion of teeth does not change jaw length.

For populations that are seasonally stable and stationary, mortality can be estimated from the growth parameters and size distributions. Recruitment appears to be periodic in sea urchins, and such periodicity can be utilized to estimate the instantaneous mortality rate per individual (Ebert 1973, 1981, 1987). Estimates of mortality also can be obtained by estimating flow rates into and out of size classes (e.g. Van Sickle 1977, Sainsbury 1982a, b) or by the fraction of a population that is in age-class 0 (Caughley 1967).

A final note is needed concerning numbers of individuals that are used in analyses. Because some animals were damaged during collection, $\mathrm{N}$ in calculations varies slightly from analysis to analysis. For example, jaws could be measured even though the test was crushed and could not be measured.

\section{RESULTS}

\section{Growth}

Growth data from the 2 pools (Fig. 2) are presented as final jaw size $\left(J_{t+1}\right)$ at time $t+1$ yr as a function of original jaw size at time $t\left(J_{t}\right)$. The scatter of data points from both areas is curvilinear. Because the data are better described with a curve rather than a straight line, the Brody-Bertalanffy model is not appropriate for modeling growth of sea urchins. A more suitable 
Fig. 2. Strongylocentrotus franciscanus. Initial and final jaw sizes of the red sea urchin tagged at 2 sites on San Nicolas Island, California; time, $t$, is $1 \mathrm{yr}_{\text {; }}$ original jaw length, $\mathrm{Jaw}(t)$, is the length at time of collection in 1990 minus the growth increments at each end of the jaw based on tetracycline marks and so is the size of the jaw in 1989

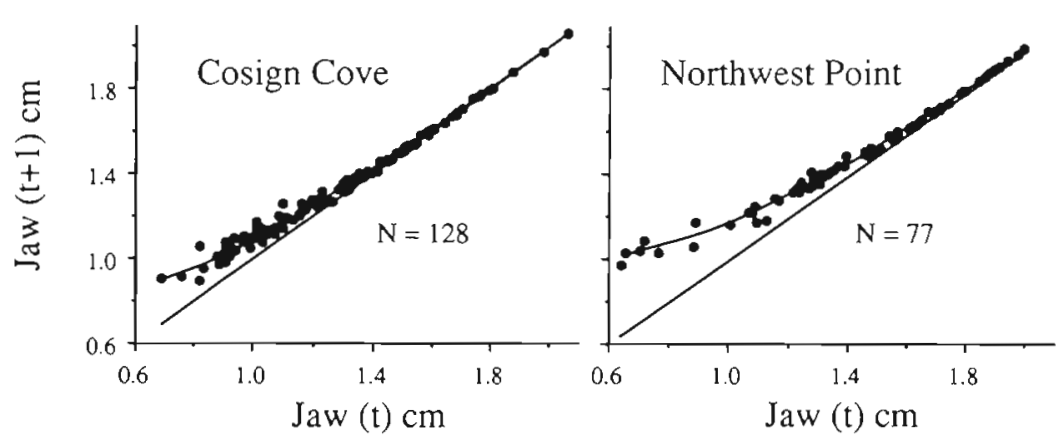

model is the Richards or Chapman-Richards function (Richards 1959, Chapman 1961, Ricker 1975).

$$
J_{i}=J_{\infty}\left(1-b e^{-K t}\right)^{-n}
$$

where $J_{t}=$ jaw length at age $t_{;} J_{\infty}=$ asymptotic jaw length $K=$ the growth rate constant in units of time $e^{-1}$; $t=$ time; $n=$ the shape parameter; and

$$
b=\frac{J_{\infty}^{-1 / n}-J_{\mathrm{R}}^{-1 / n}}{J_{\infty}^{-1 / n}}
$$

where $J_{R}=$ the size of the jaw at recruitment to the population of animals that grow according to Eq. (1) Were the Brody-Bertalanfy equation appropriate, the shape parameter, $n$, would be equal to -1 A shape parameter of +1 would indicate logistic growth.

The Richards function has been used to describe the growth of other species of sea urchins (Ebert 1980a, 1982, Russell 1987) and can be algebraically manipulated to form a difference equation that is appropriate for analyzing tagging data:

$$
J_{t+1}=\left[J_{22}^{-1 / n}\left(1-\mathrm{e}^{-K}\right)+J_{t}^{-1 / n} \mathrm{e}^{-K}\right]^{-n}
$$

where $J_{1+1}$ is the linear jaw size 1 yr after tagging, and $b$, Eq. (2), has dropped out of the equation (Ebert 1980a). Eq. (3) describes the curves fitted to the growth data (Fig. 2). The parameters $n, K$, and $J_{\infty}$ can be estimated by non-linear regression (Table 1 ) and there are commercial software packages that can do this such as NONLIN (Wilkinson 1987) or BMDPAR (Ralston 1985), which is the program we used.

Parameters for jaw growth were converted to growth parameters for the test diameter (Ebert 1982, Russell 1987) first by determining the allometric relationship between the test diameter $(D)$ and jaw length $(J)$ :

$$
D=\alpha J^{\beta}
$$

The 2 sites (Fig. 3) are not significantly different with respect to diameter versus jaw allometry (ANCOVA, $p>0.05$ ) and so a combined allometric equation was constructed using a geometric mean (GM) functional regression (Ricker 1973):

$$
D=4.4094 J^{12437}
$$

Maximum jaw size $\left(J_{\infty}\right)$ and shape parameter $n(j)$ estimates for jaw growth obtained from non-linear regression (Table 1) were used with Eq. (5) to calculate $D_{\infty}$ (asymptotic test diameter) and the shape parameter for test growth, $n(d)$ :

$$
\begin{aligned}
D_{\infty} & =4.4094 J_{\infty}{ }^{12437} \\
n(d) & =1.2437 n(j)
\end{aligned}
$$

\begin{tabular}{|c|c|c|c|c|}
\hline \multirow{2}{*}{ Parameter } & \multicolumn{2}{|c|}{ Cosign Cove, $N=127$} & \multicolumn{2}{|c|}{ Northwest Pt., $N=77$} \\
\hline & Estimate & SE & Estimate & SE \\
\hline \multicolumn{5}{|c|}{ Demi-pyramid (jaw) } \\
\hline$n$ & -0.2777 & 0.0320 & -0.2579 & 0.0182 \\
\hline$K \mathrm{yr}^{-1}$ & 0.0634 & 0.0175 & 0.0926 & 0.0195 \\
\hline$J_{\infty} \mathrm{cm}$ & 1.7376 & 0.0658 & 1.8243 & 0.0520 \\
\hline \multicolumn{5}{|c|}{ Test diameter } \\
\hline$n$ & -0.3454 & & -0.3208 & \\
\hline$D_{\infty}$ & 8.765 & & 9.312 & \\
\hline
\end{tabular}

Table 1. Strongylocentrotus franciscanus. Richards function parameters for jaw growth of the red sea urchin at 2 sites on San Nicolas Island, California; animals were tagged in 1989 and collected in $1990 ; n=$ shape parameter; $K=$ growth rate constant; $J_{\infty}=$ asymptotic jaw length 


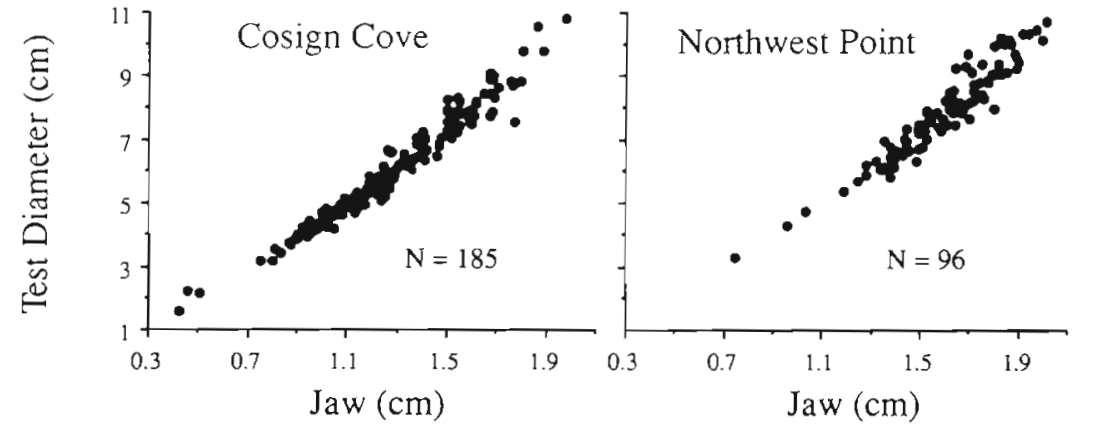

Fig. 3. Strongylocentrotus franciscanus. Test diameter versus jaw length for red sea urchins, at 2 intertidal sites on San Nicolas Island; measurements based on tests cleaned with sodium hypochlorite
Substituting $D_{\infty}$, (from Eq. 6), and an adjusted shape parameter, $n(d)$ (from Eq. 7), in the Richards function produces a growth equation for test diameter. The resulting equations for diameters in centimeters as functions of time in years for intertidal red sea urchins at San Nicolas Island are:

$$
D_{t}=8.7652\left(1-\mathrm{e}^{-0.0634 t}\right)^{0.3454}
$$

for Cosign Cove and

$$
D_{t}=9.3123\left(1-\mathrm{e}^{-0.0926 t}\right)^{03208}
$$

for Northwest Point.

Eqs. (8) \& (9) were used to construct growth curves relating test diameter as a function of age for the 2 sites (Fig. 4). Size at settlement is $0.05 \mathrm{~cm}$ (Cameron \& Schroeter 1980, Rowley 1990) and so the parameter $b$ is 0.999999 , which is rounded to 1.0 and so $b$ does not appear in the equations for sea urchins at either Cosign Cove or Northwest Point.

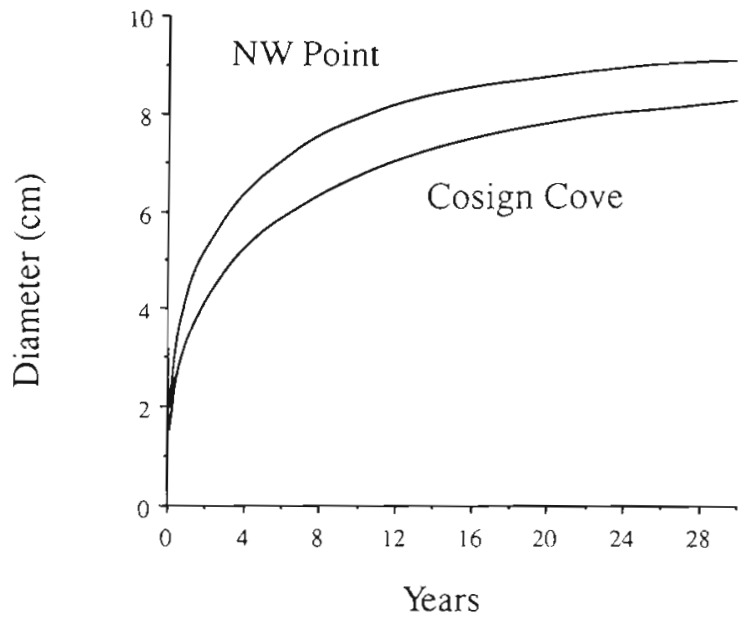

Fig. 4. Strongylocentrotus franciscanus. Growth curves for red sea urchins, at 2 sites on San Nicolas Island, California curves are based on Richards function growth parameters estimated from individuals tagged with tetracycline

\section{Mortality}

Mortality was estimated by 3 different methods that make use of the size distributions. Methods 1 and 2 use growth information. Method 1 uses the Richards function as a growth model and Method 2 uses size transitions without recourse to a specific model. Method 3 uses just size-frequency data.

Method 1. Recruitment appears to be periodic in sea urchins (Rowley 1989, 1990, Harrold et al. 1991) and such periodicity can be utilized to estimate the instantaneous mortality rate per individual, Z (Ebert 1973, $1981,1987)$. Average size of individuals, $\overline{D_{t}}$ at some time $t$ after annual recruitment is a function of $K, D_{\infty}$ $n$, and $Z$ :

$$
\overline{D_{t}}=D_{\infty}\left(1-\mathrm{e}^{-Z}\right) \sum_{1=0}^{\infty} \mathrm{e}^{-Z_{i}}\left(1-b^{i} \mathrm{e}^{-K(t+i)}\right)^{-n}
$$

Solving for growth and survival parameters has been cast as the solution of a system of simultaneous equations (Ebert 1973, Damm 1987) but when there are more determinations of mean size than parameters to be estimated, the problem becomes one of non-linear regression in which mean diameter is the dependent variable (Eq. 10) and one or more parameters can be estimated. Because Richards function parameters were estimated from tagging, just the mortality coefficient, $Z$, has to be estimated. The parameter $b^{\prime}$ has a meaning that is slightly different from the meaning of $b$ in Eqs. (1) \& (2) where it is based on the size at which animals begin to grow according to the growth equation. The parameter $b^{\prime}$ is based on the size of individuals at some specified time that may or may not be at the time of settlement:

$$
b^{\prime}=\frac{\left(D_{\infty}^{-1 / n}-D_{\mathrm{R}}^{-1 / n}\right)}{D_{\infty}^{-1 / n}}
$$

Time, $t$, is the time after recruitment and is set equal to zero so $D_{R}$, the diameter at recruitment, can be set equal to the mean size of new recruits at the time that 


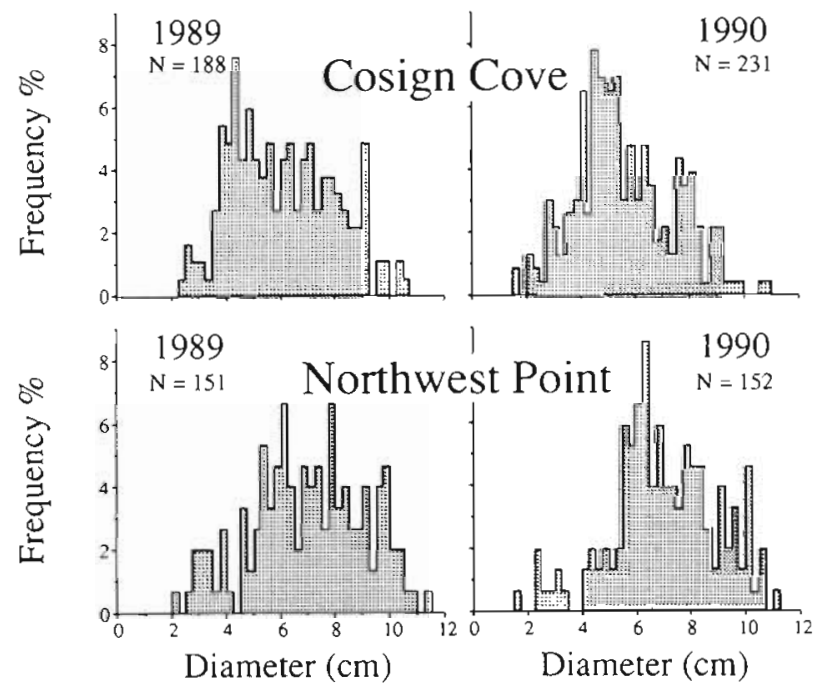

Fig. 5. Strongylocentrotus franciscanus. Size distributions of intertidal sea urchins at Cosign Cove and Northwest Point on San Nicolas Island; mean sizes for Cosign Cove are $6.10 \mathrm{~cm}$ (1989) and $5.66 \mathrm{~cm}(1990)$; mean sizes for Northwest Point are $7.01 \mathrm{~cm}(1989)$ and $7.02 \mathrm{~cm}(1990)$

size distributions were measured, that is, late March and early April. This adjustment avoids the problem of having to know the actual age of the animals in the first mode of the size distribution and means that if samples had been gathered at some other time of year, $D_{\mathrm{R}}$ and hence $b^{\prime}$ would have been different but time, $t$, still would be set equal to zero. Based on the growth equations and apparent modes in Fig. 5, we selected all individuals $<3.50 \mathrm{~cm}$ for Cosign Cove and $<3.75 \mathrm{~cm}$ for Northwest Point as being new recruits. Mean size for new recruits at Cosign Cove is $2.767 \mathrm{~cm}$ ( $\mathrm{SD}=0.477$ ), and is $2.845 \mathrm{~cm}(\mathrm{SD}=0.476)$ at Northwest Point. It is reasonable to use $2.80 \mathrm{~cm}$ as an estimate for both sites The program written by Ebert (1987) was used to estimate $Z$ using means for 1989 and 1990 for each site (Table 2). For Cosign Cove, $Z=0.106$; for Northwest Point, $Z=0.088$. Annual mortality rate and $Z$ are related:

$$
\text { Annual mortality rate }=1-\mathrm{e}^{-z}
$$

so the annual mortality rates are 0.10 and 0.08 , respectively, for the 2 sites.

Sensitivity of the estimate of $Z$ to changes in mean size $\left(\overline{D_{1}}\right)$ and size at recruitment $\left(D_{\mathrm{R}}\right)$ was explored by using the $95 \%$ confidence limits for mean size and $\pm 10 \%$ of the size at recruitment. Results (Table 2) show that the estimate of $Z$ is sensitive to these changes and more sensitive to changes in mean size than to changes in size at recruitment. The proportional changes, or elasticities (de Kroon et al. 1986), are 4.5 for mean size and about 0.53 for size at recruitment: a $10 \%$ change in mean size would cause a $45 \%$ change in $Z$, but a $10 \%$ change in size at recruitment $\left(D_{\mathrm{R}}\right)$ would produce only a $5 \%$ change in $Z$. Overall, both Cosign Cove and Northwest Point have values of $Z$ that are about 0.1 . However, differences are apparent at the second decimal place and survival may be somewhat better at Northwest Point.

Method 2. Estimates of $Z$ can be obtained based on transfers of individuals from one size class to another and can be dependent on (e.g. Van Sickle 1977, Schnute et al. 1989) or independent of (e.g. Brown 1975) a growth function. If estimates of density are available, it is possible to remove the assumption of seasonally stationary size structure (e.g. Sainsbury

Table 2. Strongylocentrotus franciscanus. Sensitivity of estimates of survival rate per individual $(Z)$ to changes in mean size $\left(\overline{D_{l}}\right)$ and size at recruitment $\left(D_{R}\right)$

\begin{tabular}{|c|c|c|c|c|c|}
\hline & 1989 & 1990 & $D_{\mathrm{R}}$ & $z$ & SE \\
\hline \multicolumn{6}{|l|}{ Cosign Cove } \\
\hline$N$ & 188 & 231 & & & \\
\hline$\overline{D_{1}} \pm \mathrm{SD}$ & $6.098 \pm 1.886$ & $5.658 \pm 1.825$ & 2.80 & 0.106 & 0.017 \\
\hline Lower $95 \% \overline{D_{l}}$ & 5.827 & 5.422 & 2.80 & 0.127 & 0.019 \\
\hline Upper $95 \% \overline{D_{t}}$ & 6.369 & 5.894 & 2.80 & 0.087 & 0.015 \\
\hline$\overline{D_{i}}$ upper $95 \% D_{\mathrm{R}}$ & 6.098 & 5.658 & 2.50 & 0.100 & 0.016 \\
\hline $\bar{D}_{1}$, lower $95 \% D_{R}$ & 6.098 & 5.658 & 3.00 & 0.110 & 0.018 \\
\hline \multicolumn{6}{|l|}{ Northwest Point } \\
\hline $\mathrm{N}$ & 151 & 152 & & & \\
\hline$\overline{D_{1}} \pm \mathrm{SD}$ & $7.014 \pm 2.061$ & $7.015 \pm 1.959$ & 2.80 & 0.088 & $<0.001$ \\
\hline Lower $95 \% \overline{D_{l}}$ & 6.683 & 6.701 & 2.80 & 0.111 & 0.001 \\
\hline Upper $95 \% \overline{D_{l}}$ & 7.345 & 7.329 & 2.80 & 0.069 & $<0.001$ \\
\hline$\overline{D_{t}}$, upper $95 \% D_{\mathrm{R}}$ & 7.014 & 7.015 & 2.50 & 0.086 & $<0.001$ \\
\hline$\overline{D_{t}}$, lower $95 \% D_{\mathrm{R}}$ & 7.014 & 7.015 & 3.00 & 0.091 & $<0.001$ \\
\hline
\end{tabular}


$1982 a$, b). We will use our growth data without assuming any particular growth model and because no density measurements were made, we must assume seasonally stable and stationary structure. Sizespecific survival rates are the corrections to a growth transition matrix that are needed in order to produce terms of the stable-size distribution. No growth model is required but the approach suffers from the effects of small numbers of observations in size classes.

The data in Fig. 2 were grouped into size classes so the rates of growth from one size class to another could be described without recourse to any particular growth model. Eq. (4) was modified to calculate original diameter based on the change in jaw length $(J)$ over a period of 1 yr and final diameter $\left(D_{t+1}\right)$ :

$$
D_{i}=D_{t+1}-4.4094\left(J_{t+1}^{1.2437}-J_{t}^{12437}\right)
$$

Two general features are evident (Table 3): (1) for both Cosign Cove and Northwest Point, all individuals with diameters $<4.00 \mathrm{~cm}$ in 1989 grew out of this class into the 4.01 to $6.00 \mathrm{~cm}$ size class; (2) over one-third of the transitions have 5 or fewer individuals

Unweighted, average size-frequency distributions were constructed using the same size intervals as shown in Table 3 by combining size frequencies for 1989 and 1990 and dividing by 2 . For Cosign Cove, the average size-frequency vector is

$$
\begin{aligned}
& <4.00 \mathrm{~cm} \\
& 4.01-6.00 \mathrm{~cm} \\
& 6.01-8.00 \mathrm{~cm} \\
& >8.00 \mathrm{~cm}
\end{aligned} \quad\left(\begin{array}{l}
0.143 \\
0.419 \\
0.278 \\
0.159
\end{array}\right)
$$

and, for Northwest Point, the vector is:

$$
\left.\begin{array}{l|l}
<4.00 \mathrm{~cm} & 0.074 \\
4.01-6.00 \mathrm{~cm} & 0.214 \\
6.01-8.00 \mathrm{~cm} & 0.388 \\
8.00-10.00 \mathrm{~cm} & 0.254 \\
>10.00 \mathrm{~cm} & 0.070
\end{array}\right)
$$

We assume that the population is stable and stationary so if the transition matrix is multiplied by the stablesize distribution, the resulting vector must, once again, be equal to the stable-size distribution (Eq. 16).

$$
\left(\begin{array}{cccc}
- & - & - & - \\
1.0 & 0.891 & 0 & 0 \\
0 & 0.109 & 0.915 & 0 \\
0 & 0 & 0.0851 & 1.0
\end{array}\right)\left(\begin{array}{l}
0.143 \\
0.419 \\
0.278 \\
0.154
\end{array}\right)=\left(\begin{array}{c}
- \\
0.517 \\
0.300 \\
0.182
\end{array}\right)
$$

The first element in the stable-size distribution is due to recruitment, which would have to be generated by having fecundity values in the first row of the matrix. The product of the first row of the transition matrix and the stable-size distribution vector would be equal to 0.143 for Cosign Cove and is shown in a box in
Eq. (17). The other terms in the resultant vector must be multiplied by appropriate survival constants in order to equal the stable-size distribution.

$$
\left(\begin{array}{c}
- \\
0.517 s_{1} \\
0.300 s_{2} \\
0.182 s_{3}
\end{array}\right)=\left(\begin{array}{l}
0.143 \\
0.419 \\
0.278 \\
0.154
\end{array}\right)
$$

Values of $\boldsymbol{s}$ are the size-specific survival rates that are consistent with the stable- and stationary-size distribution. For example, $s_{1}$ is $0.419 / 0.517$ or 0.811 (Eq. 18).

$$
\left(\begin{array}{l}
- \\
s_{1} \\
s_{2} \\
s_{3}
\end{array}\right)=\left(\begin{array}{c}
- \\
0.811 \\
0.927 \\
0.878
\end{array}\right)
$$

There is no obvious trend in the size-specific rates so a mean value probably is appropriate. Weighting values in $s$ by the marginal totals in Table 3 gives a mean annual survival of 0.869 so $Z=0.141$ (Eq. 12).

In a similar manner, the growth-transition matrix for Northwest Point was multiplied by the stable-size vector and the resultant vector was corrected in order once again to be equal to the stable-size distribution (Eqs. 19 to 21 )

$$
\begin{gathered}
\left(\begin{array}{ccccc}
- & - & - & - & - \\
1.0 & 0.421 & 0 & 0 & 0 \\
0 & 0.579 & 0.968 & 0 & 0 \\
0 & 0 & 0.032 & 0.941 & 0 \\
0 & 0 & 0 & 0.059 & 1.0
\end{array}\right)\left(\begin{array}{l}
0.083 \\
0.212 \\
0.384 \\
0.252 \\
0.069
\end{array}\right)=\left(\begin{array}{c}
- \\
0.172 \\
0.494 \\
0.249 \\
0.084
\end{array}\right) \\
\left(\begin{array}{c}
- \\
0.172 s_{1} \\
0.494 s_{2} \\
0.249 s_{3} \\
0.084 s_{4}
\end{array}\right)=\left(\begin{array}{l}
0.083 \\
0.212 \\
0.384 \\
0.252 \\
0.069
\end{array}\right) \\
\left(\begin{array}{c}
- \\
s_{1} \\
s_{2} \\
s_{3} \\
s_{4}
\end{array}\right)=\left(\begin{array}{c}
- \\
1.230 \\
0.777 \\
1.010 \\
0.824
\end{array}\right)
\end{gathered}
$$

Like the results for Cosign Cove, there is no trend in the size-specific survival rates so a mean value is appropriate. Weighting values in $s$ by the marginal totals in Table 3 gives a mean annual survival rate of 0.914 so $Z=0.090$. Elements of $s$ (Eq. 21) that are greater than 1.0 are not possible and, most likely (Van Sickle 1977), are caused by the small numbers of individuals in the classes shown in Table 3 .

Method 3. Finally, $Z$ can be estimated by the fraction of juveniles in the population (Caughley 1967, Ebert 1982) assuming, once again, a stable and stationary configuration in which mortality is balanced by recruitment. As in Method 1, all individuals with test diame- 
Table 3. Strongylocentrotus franciscanus. Growth transitions from 1989 to 1990 of individual at 2 sites on San Nicolas Island, California original size of tagged individuals determined by Eq. (13)

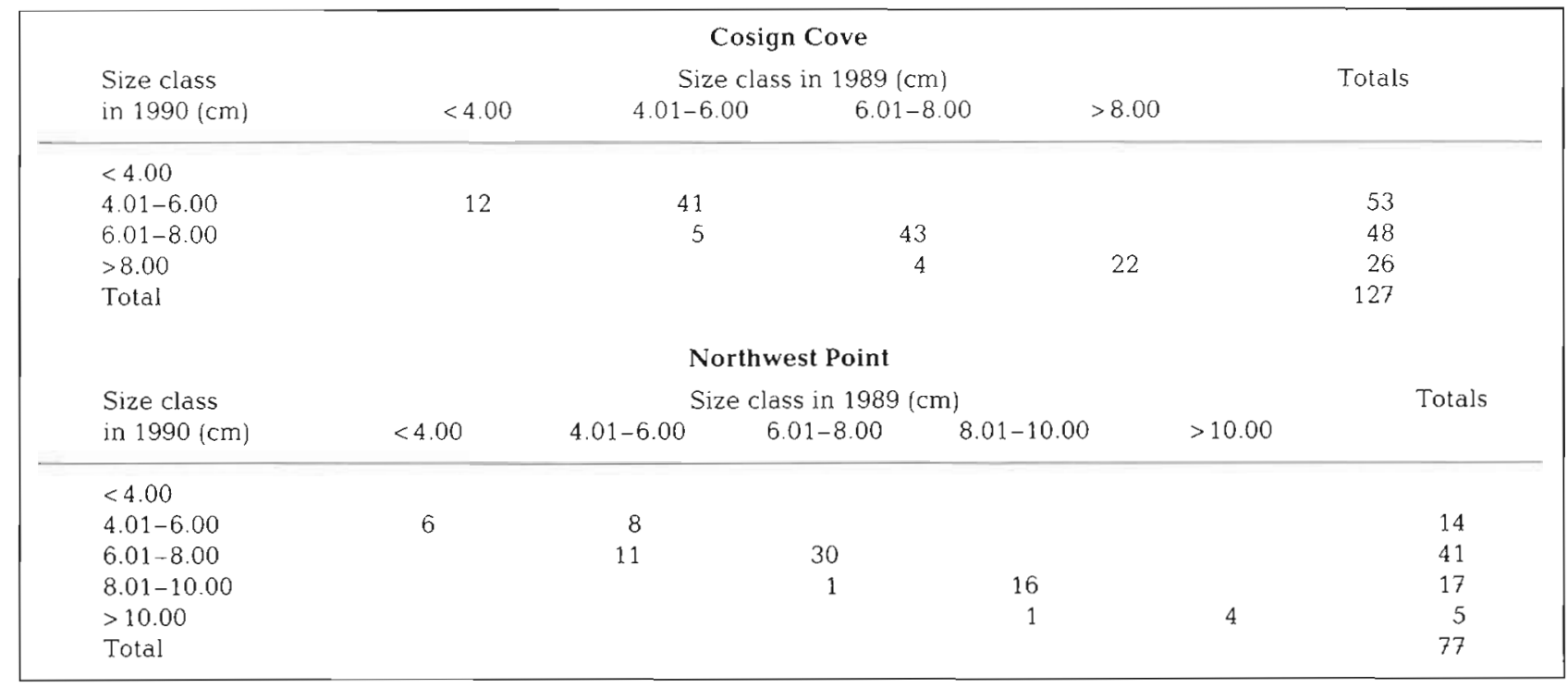

ters $\leq 3.50 \mathrm{~cm}$ at Cosign Cove and $\leq 3.75 \mathrm{~cm}$ at Northwest Point were considered to be age-0. For Cosign Cove in 1989, there were 9 age-0 individuals in a sample of 188 so the fraction in 0.048 . In 1990 , the fraction is $23 / 231$ or 0.100 so the average annual recruitment or mortality rate is 0.074 . For Northwest Point, the fractions are $12 / 151$ in 1989 and $10 / 153$ in 1990 for a mean annual rate of 0.072 . The annual mortality rate is about $7 \%$ for both sites (Table 4 ) and, using Eq. (12), $Z=0.076$ and 0.075 for Cosign Cove and Northwest Point respectively.

Of the 3 methods, Method 1 uses the most detailed information about growth; size is summarized as a mean so small numbers of particular sizes are much less important than in Method 2. Use of a mean in Method 1 also tends to reduce the influence of numbers of individuals at age- 0 , which are the only data of importance in Method 3.

Relative robustness can be illustrated by comparing Methods 1 and 3. For example, the mean size of animals at Cosign Cove in 1989 was $6.098 \mathrm{~cm}$ and the lower $95 \%$ confidence limit is $5.827 \mathrm{~cm}$. The question is, how many animals of average size must be removed and replaced by age- 0 individuals in order to have the mean drop from 6.098 to 5.827 ? The sum of sizes of the 188 animals in 1989 was 1146.42 and, if the mean is 5.827 , then the sum of sizes for 188 animals must be 1095.48. The difference is $1146.42-1095.48=50.94$, which when divided by 2.80 gives 18 , the number of average sized individuals that must be removed and replaced by age- 0 animals. The actual number of age-0 animals in the Cosign Cove sample in 1989 was 9 to which the 18 must be added to give the new number, 27, of age-0 individuals. The new estimate of annual mortality is $27 / 188$ or 0.144 so $Z=0.155$. This is an increase of $103.9 \%$ so a $4.4 \%$ drop in mean size due to an unusual recruitment year changes the estimate of $Z$ (Eq. 12) by $104 \%$. The elasticity is 23.6 , which means that a $10 \%$ change in mean size due to an increase or decrease in recruitment will change the estimate of $Z$ by about $236 \%$. Method 1 is much more robust than Method 3.

Method 2 is very attractive because of the possibility of estimating size-specific survival and, with the addition of density data, to discard the assumption of stable and stationary structure for the population. The single greatest problem is the small number of individuals that appear in some of the cells. One solution would be to combine size classes; however, 4 or 5 classes is already very small. The obvious solution would be to increase $N$, and Table 3 suggests that an increase of about 3 to 5 times might be adequate for 4 to 5 classes. Such an increase should make all elements in Table 3 $\geq 10$. For Cosign Cove, with 127 animals in the sample, multiplying by 3 would achieve the goal and, for

Table 4. Strongylocentrotus franciscanus. Summary of estimates of $Z$ for red sea urching at 2 sites on San Nicolas Island, California, using 3 methods; annual mortality rate is $1-\mathrm{e}^{-Z}$

\begin{tabular}{ccc|}
\hline Method & Cosign Cove & Northwest Point \\
\hline 1 & 0.106 & 0.083 \\
& $(0.087-0.127)$ & $(0.069-0.111)$ \\
3 & 0.141 & 0.090 \\
& 0.076 & 0.075 \\
\hline
\end{tabular}


Northwest Point, it would be necessary to increase the sample by an order of magnitude. As a reasonable compromise, 500 tagged individuals with good size dispersion would be adequate for the analysis. Any further increase in $N$ would permit the addition of more size categories and hence increase the resolution of size-specific rates. Depending on recovery rate, it would be necessary to tag and collect one to several thousand individuals. We conclude that, of the methods presented here, Method 1 provides the best estimates of $Z$.

\section{DISCUSSION}

There are no published estimates of growth and mortality for Strongylocentrotus franciscanus that can be used for direct comparison with our work; however, data sets in 2 unpublished theses can be reanalyzed using the same methods described here. Data have been reanalyzed that were gathered by Baker (1973, unpubl.) at subtidal sites off San Diego, California, $\left(32^{\circ} \mathrm{N}\right.$ ) (Table 5) and by Low (1975) at subtidal sites off Saltspring Island $\left(48^{\circ} \mathrm{N}\right)$ in the Strait of Georgia, British Columbia (Table 6). Baker selected 1 site on the north jetty of Mission Bay and 2 sites at Point Loma (a reef ledge and the outfall pipe for the San Diego sewer system), used invasive tags (Ebert 1965) and recovered very small numbers of individuals after $1 \mathrm{yr}$. The estimates of $Z$ (Eq. 10) for the reef site at Point Loma and Mission Bay bracket the estimates obtained for San Nicolas Island. Applying growth estimates for the reef site to the sample from the sewer outfall at Point Loma gives a very unreasonable estimate for $Z$ of $0.006 \mathrm{yr}^{-1}$. Using the fraction of individuals at age-0 gives estimates of $Z$ of 0.092 for Mission Bay animals and 0.373 and $0.000 \mathrm{yr}^{-1}$ for the reef and outfall animals at Point Loma. The analysis of Baker's data suffers from several problems: (1) small numbers of recaptures; (2) probable interference of growth by the invasive tags;
(3) possibly unusual recruitment at Point Loma. Our point is that Baker's study provides the only comparative information on Strongylocentrotus franciscanus growth and survival in the field and the data sets, for a variety of reasons, yield estimates that lack internal consistency.

Data gathered by Low (1975) can be used to estimate growth (Table 6) but not survival because size data were gathered to emphasize maximum and minimum sizes and were not intended to reflect true proportions in the field. Data related to growth are of 3 types: animals marked with invasive body tags, animals held in enclosures, and free-roaming individuals. Rocks were marked on the bottom near clumps of large animals and all individuals were measured in 1972 and again in 1974. Because of unequal time intervals, Fabens' (1965) method was used to estimate growth parameters and so the shape parameter, $n$, was assumed to be -1 . Growth estimates for sites on Saltspring Island suggest very slow growth: $K=0.072 \mathrm{yr}^{-1}$ and $D_{\infty}=18.64 \mathrm{~cm}$, which implies that size is $1.33 \mathrm{~cm}$ at $1 \mathrm{yr}, 2.57 \mathrm{~cm}$ at $2 \mathrm{yr}$ and $3.72 \mathrm{~cm}$ at $3 \mathrm{yr}$. The invasive tags certainly interfere with growth but fenced animals that were not tagged also showed very slow growth from a mean of $2.4 \mathrm{~cm}$ in 1972 to only $4.8 \mathrm{~cm}$ in 1974 . Growth of small red sea urchins may actually be this slow in British Columbia, or the data are an example of how fences modify natural conditions.

Growth of Strongylocentrotus franciscanus at San Nicolas Island can be compared with intertidal populations of $S$. purpuratus studied from Vancouver Island (Canada), San Diego, California (USA), and Punta Baja (Mexico) (Russell 1987). Strongylocentrotus purpuratus is smaller than $S$. franciscanus and has shape parameters of the Richards function (mean $n=-0.218$ $\pm 0.012(\mathrm{SE})$, range $=-0.183$ to $-0.261, \mathrm{~N}=8$ ) which are smaller than those found for $S$. franciscanus at San Nicolas Island ( -0.321 and -0.345 ; Eqs. 8 \& 9). Nineteen determinations of $n$ for tropical and subtropical species (Ebert 1982) provide an estimate of $n=-0.384$

Table 5. Strongylocentrotus franciscanus. Analysis of 1972 data from Point Loma $\left(32^{\circ} 40^{\prime} N\right)$ and Mission Bay (32 $\left.45^{\prime} N\right)$, San Diego, California (Baker 1973); asymptotic diameter $\left(D_{\mathrm{m}}\right)$, mean diameter $\left(\overline{D_{t}}\right)$ and mean size of recruits on date of sampling $\left(D_{\mathrm{R}}\right)$ are in centimeters; $K$ and $Z$ are in units of $\mathrm{yr}^{-1} ; N_{T}$ is total number in the size distribution $N_{0}$ is number in the first mode $Z_{1}$ and $Z_{2}$ were determined using Eqs. (10) \& (12) respectively

\begin{tabular}{|c|c|c|c|c|c|c|c|c|c|c|c|}
\hline \multirow[t]{2}{*}{ Site } & \multicolumn{4}{|c|}{ Growth analysis } & \multirow[t]{2}{*}{ Date } & \multicolumn{6}{|c|}{ Size distribution analysis } \\
\hline & $N$ & $D_{\infty}$ & $K$ & $n$ & & $N_{T}$ & $N_{0}$ & $\overline{D_{i}}$ & $D_{\mathrm{R}}$ & $Z_{1}$ & $Z_{2}$ \\
\hline Mission Bay & 24 & 9.05 & 0.048 & -0.228 & 26 Feb 1972 & 152 & 14 & 7.13 & 2.94 & 0.055 & 0.092 \\
\hline \multicolumn{12}{|l|}{ Point Loma } \\
\hline Reef & 23 & 11.03 & 0.215 & -0.810 & 17 Apr 1972 & 75 & 28 & 7.03 & 2.94 & 0.187 & 0.373 \\
\hline Outfall & & & & & $2 \operatorname{Mar} 1972$ & 156 & 0 & 10.80 & $2.94^{\mathrm{a}}$ & 0.006 & 0.000 \\
\hline
\end{tabular}


Table 6. Strongylocentrotus franciscanus. Analysis of 1972 to 1974 data from Saltspring Island (48 50' N) (Low 1975). Asymptotic diameter $\left(D_{\infty}\right)$ is in centimeters; $K$ in units of yr ${ }^{1}$; animals were tagged 4 May 1972 and collected 17 February 1973; small animals in fenced areas were set up 14 March 1972 and measured on 20 January 1973 and 19 March 1974; free-roaming large animals near marked rocks were measured on 13 March 1972 and again on 30 March 1974. Brody-Bertalanffy parameters using Fabens' (1965) method, so $n=-1: K=0.074 \mathrm{yr}^{-1} \pm 0.018$ (SE) and $D_{\infty}=18.64 \mathrm{~cm} \pm 2.798$ (SE); standard error estimates based on Sims (1985)

\begin{tabular}{|lcccc|}
\hline Treatment & Initial size range & $\mathrm{N}$ & Final size range & $\Delta$ time \\
\hline Tagged & $3.7-13.7 \mathrm{~cm}$ & 12 ind. & $5.0-14.0 \mathrm{~cm}$ & $0.8 \mathrm{yr}$ \\
Fenced & $1.8-3.3 \mathrm{~cm}$ & 5 plots & $\bar{x}=4.5-5.1 \mathrm{~cm}$ & $2 \mathrm{yr}$ \\
Free & $\bar{x}=11.23-13.14$ & 4 sites & $\bar{x}=12.20-13.70 \mathrm{~cm}$ & $2 \mathrm{yr}$ \\
\hline
\end{tabular}

\pm 0.063 (SE), which suggests that the shape of the growth curve of $S$. franciscanus is more like other sea urchin genera than like its congener $S$. purpuratus.

A final growth comparison focuses on the very large size of Strongylocentrotus franciscanus. The question is, how does size at $1 \mathrm{yr}$, when reproduction begins, compare with maximum size? The ratio of $D_{1} / D_{\infty}$ is a dimensionless number that may provide insight into the evolution of echinoid life histories (cf. Charnov 1991). The ratio of $D_{1} / D_{\infty}$ is 0.376 for the sample from Cosign Cove and 0.462 for animals at Northwest Point. For comparison, 18 samples of tropical and subtropical sea urchins (Ebert 1982) have a $D_{1} / D_{\infty}$ ratio of $0.476 \pm 0.024(\mathrm{SE})$ with a range of 0.184 to 0.591 . The fraction of maximum growth achieved by $S$. franciscanus at San Nicolas Island in the first year of life seems to be typical of other echinoid species and so the shape of the growth curve does not appear to be part of the explanation of the unusually large maximum size.

Comparisons of survival with other sea urchin species can be made first with its congener Strongylocentrotus purpuratus from intertidal sites from Canada to Mexico (Russell 1987). Average values of $Z$ from Vancouver Island (British Columbia), San Diego (California), and Punta Baja (Baja California Norte) are $0.12,0.20$, and 0.32 , respectively, which suggest somewhat better survival, and hence longer life, for $S$. franciscanus than for $S$. purpuratus.

A second comparison is based on the relative size of the body wall of Strongylocentrotus franciscanus and exposure to waves. Annual survival rate $(p)$ of 17 tropical and sub-tropical species with a total of 38 populations (Ebert 1982) was found to be a function of wave exposure $(E)$ and the allometric coefficient of relative body wall size $(\alpha)$ :

$$
p=1.206 \alpha+0.061 E-0.350
$$

The value of $\alpha$ for Strongylocentrotus franciscanus is about 0.53 (Ebert 1982) and a subjective exposure value for both Cosign Cove and Northwest Point is about 5.0 compared with tropical and sub-tropical sites (Ebert 1982). The estimate of annual survival for
S. franciscanus at San Nicolas Island is 0.59 (Eq. 22), which is a $Z$ of 0.52 (Eq. 21) and represents unrealistically high mortality when compared with estimated rates based on growth and size structure (Table 4). In this respect, $S$. franciscanus is similar to the Australian sea urchin Heliocidaris erythrogramma which has an $\alpha$ of 0.54 , an observed $Z$ of about 0.1 but an estimated $Z$ (Eq. 22) of 0.51 (Ebert 1982). Both of these species appear to survive much better than expected based on the relative mass of their body walls and the habitats in which they live.

Causes of death of sea urchins at San Nicolas Island include potential predators such as spiny lobsters Panulirus interruptus, which would be capable of killing even the largest individuals measured in this study (Tegner \& Levin 1983), and possibly crabs and labrid fish (Tegner 1980, Cowen 1983). Both areas are exposed to the open sea and so storms probably remove some individuals. One source of mortality that probably is not important is starvation (reviewed by Andrew 1989) but growth differences between the sites provide several unresolved puzzles.

Despite the proximity of the 2 sites on San Nicolas Island, the red sea urchins from Cosign Cove and Northwest Point exhibit different growth rates. For example, based on our estimates of Richards function parameters, it would take 6 yr for an animal to reach $7 \mathrm{~cm}$ in the Northwest Point pool, whereas it would take twice as long for an urchin to achieve this size at Cosign Cove (Fig. 5). A reasonable hypothesis is that there were differences in available food, which would not be surprising considering that such small-scale differences have been shown for Strongylocentrotus purpuratus (Ebert 1968). If food differences were present, then morphological differences would be expected because sea urchins have the ability to respond physiologically and morphologically to fluctuating resources (Ebert 1980b, Black et al. 1982, 1984, Fansler 1983, Russell 1987, Levitan 1988, 1989, Edwards \& Ebert 1991). Relative size of demi-pyramids changes with available food and so can be used as an indicator of food conditions in the field (Ebert 1980b). The fact that relative jaw sizes were the same for red sea 
urchins at Cosign Cove and Northwest Point suggests that available food was the same at the 2 locations; however, jaw plasticity of red sea urchins has not been investigated and so it is also possible, though we admit that it seems unlikely, that development of Aristotle's lantern in these animals is more canalized than it appears to be in. other echinoid species that have been studied. Other environmental stresses can influence growth, such as spine damage (Ebert 1968, Edwards \& Ebert 1991); however, there is evidence (Edwards \& Ebert 1991) that spine damage may stimulate calcification throughout the skeleton, so jaws were relatively larger in animals that were forced to repair spines. At present, the reason for the growth difference of animals at the 2 sites is unknown.

There is a need to obtain information on the response of Strongylocentrotus franciscanus to changes in available food in order to determine whether it is physiologically less plastic than other species that have been studied. Also, additional growth, size, and survival data are needed at more locations and depths in order to determine whether the shape of the growth curve differs from other species and whether the low mortality rates of S. franciscanus at San Nicolas Island are typical. These data are needed to understand the life-history evolution of $S$. franciscanus relative to other species, and to develop appropriate management models for the fishery of this species from Alaska to Mexico.

Acknowledgements. Work at San Nicolas Island was possible due to cooperation from the US Navy and was supported by funds from the US Fish and Wildife Service to James Estes. Help in the field was provided by Thomas Murphy and $\mathrm{J}$. Estes. The manuscript benefitted from the comments supplied by several anonymous reviewers.

\section{LITERATURE CITED}

Andrew, N. L. (1989). Contrasting ecological implications of food limitation in sea urchins and herbivorous gastropods. Mar. Ecol. Prog. Ser. 51: 189-193

Baker, S. L. (1973). Growth of the red sea urchin Strongylocentrotus franciscanus in two natural habitats. M.Sc. thesis, San Diego State University, San Diego

Black, R., Codd, C., Hebbert, D., Vink, S., Burt, J. (1984). The functional significance of the relative size of Aristotle's Lantern in the sea urchin Echinometra mathaei (de Blainville). J. exp. mar. Biol. Ecol. 77: 81-97

Black, R., Johnson, M. S., Trendall, J. I (1982). Relative size of Aristotle's lantern in Echinometra mathaei occurring at different densities. Mar. Biol. 71: 101-106

Brown, K. M. (1975). Estimation of demographic parameters from sampling data. Am. Midl. Nat. 93(2): 454-459

Cameron, R. A., Schroeter, S. C. (1980). Sea urchin recruttment: effect of substrate selection on juvenile distribution. Mar. Ecol. Prog. Ser. 2: 243-247

Caughley, G. (1967). Calculation of population mortality rate and life expectancy for thar and kangaroos from the ratio of juveniles to adults. N.Z. J. Sci. 10:578-584
Chapman, D. G. (1961). Statistical problems in dynamics of exploited fisheries populations. In: Neyman, J. (ed.) Proc. 4th Berkeley Symp. Math. Stat. and Probability, Vol 4. Contr. Biol. and Probl. Med., Univ. California Press, Berkeley, p. 153-168

Charnov, E. L. (1991). Pure numbers, invariants and symmetry in the evolution of life histories. Evol. Ecol. 5: $339-342$

Cowen, R. K. (1983). The effect of sheephead (Semicossyphus pulcher) predation on red sea urchin (Strongylocentrotus franciscanus) populations: an experimental analysis. Oecologia 58: 249-255

Damm, U. (1987). Some modifications of Ebert's method to estimate growth and mortality parameters from average lengths in a population. In: Pauly D., Morgan, G. R. (eds.) Length-based methods in fisheries research. ICLARM Conference Proceedings 13. International Center for Living Aquatic Resources Management, Manila, and Kuwait Institute for Scientific Research, Safat, p. $45-51$

de Kroon, H., Plaisier, A, van Groenendael, J., Caswell, H. (1.986). Elasticity: the relative contribution of demographic parameters to population growth rate. Ecology 67: $1427-1431$

Ebert, T. A. (1965). A technique for the individual marking of sea urchins. Ecology 46: 193-194

Ebert, T. A. (1968). Growth rates of the sea urchin Strongylocentrotus purpuratus related to food availability and spine abrasion. Ecology 49: 1075-1091

Ebert, T A. (1973). Estimating growth and mortality rates from size data. Oecologia 11.281-298

Ebert, T A. (1977). An experimental analysis of sea urchin dynamics and community interactions on a rock jetty. J. exp. mar. Biol. Ecol. 27: 1-22

Ebert, T A. (1980a). Estimating parameters in a flexible growth equation, the Richards function. Can. J. Fish. Aquat. Sci. 37: 687-692

Ebert, T A. (1980b). Relative growth of sea urchin jaws: an example of plastic resource allocation. Bull. mar. Sci. 30: $467-474$

Ebert, T. A. (1981). Estimating mortality from growth parameters and a size distribution when recruitment is periodic. Limnol. Oceanogr. 26: 764-769

Ebert, I A. (1982). Longevity, life history, and relative body wall sıze in sea urchins. Ecol. Monogr. 54: 353-394

Ebert, T A. (1987). Estimating growth and mortality parameters by nonlinear regression using average size in catches. In: Pauly D., Morgan, G. R. (eds.) Length-based methods in fisheries research. ICLARM Conference Proceedings 13. International Center for Living Aquatic Resources Management, Manila, and Kuwait Institute for Scientific Research, Safat, p. 35-44

Ebert, T A. (1988). Calibration of natural growth lines in ossicles of two sea urchins, Strongylocentrotus purpuratus and Echinometra mathael, using tetracycline. In: Burke, R. D., Mladenov, P. V., Lambert, P., Parsley, T. L. (eds.) Echinoderm biology. A. A Balkema, Rotterdam, p. 435-443

Edwards, P. B. Ebert, T A. (1991). Plastic responses to limited food availability and spine damage in the sea urchın Strongylocentrotus purpuratus. J. exp. mar. Biol. Ecol. 145: 295-220

Fabens, A. J. (1965). Properties and fitting of the von Bertalanffy growth curve. Growth 29: 265-289

Fansier, S. C. (1983). Phenotypic plasticity of skeletal elements in the purple sea urchin, Strongylocentrotus purpuratus. M.Sc. thesis, San Diego State University, San Diego 
Harrold, C., Lisin, S., Light, K. H., Tudor, S. (1991). Isolating settlement from recruitment of sea urchins. J. exp. mar Biol. Ecol. 147: 81-94

Harrold, C., Pearse, J. S. (1987). The ecological role of echinoderms in kelp forests. In: Jangoux, M., Lawrence, J, M (eds.) Echinoderm studies II. A. A. Balkema, Rotterdam, p $137-233$

Kato, S., Schroeter, S. C. (1985). Biology of the red sea urchin. Strongylocentrotus franciscanus, and its fishery in Caljfornia. Mar. Fish. Rev, 47: 1-20

Kramer, D. E., Nordin, D. M. A. (1975). Physical data from a study of size, weight and gonad quality for the red sea urchin (Strongylocentrotus franciscanus (Agassiz)) over a one-year period. MS Rep. Ser. Fish. Res. Bd Can. 1372 $1-91$

Lawrence, J. M. (1975). On the relationships between marine plants and sea urchins. Oceanogr. mar. Biol. A. Rev. 13: $213-286$

Leighton, D. L. (1967). Ecological investigations of sea urchin populations along the Palos Verdes peninsula. In: North, W. J. (principal investigator) Kelp habitat improvement project, Ann. Rep. 1966-67. Calif. Inst. Technol., Pasadena, p. 41-54

Leighton, D. L. (1968). Ecological investigations of sea urchin populations along the Palos Verdes peninsula. In: North, W. J. (principal investigator) Kelp habitat improvement project, Ann. Rep. 1967-68. Calif. Inst. Technol., Pasadena, p. 39-62

Levitan, D. R. (1988). Density-dependent size regulation and negative growth in the sea urchin Diadema antillarum Philippi. Oecologia 76: 627-629

Levitan, D. R. (1989). Density-dependent size regulation in Diadema antillarum: effects on fecundity and survivorship. Ecology 70: 1414-1424

Low, C. J. (1975). The effect of grouping of Strongylocentrotus franciscanus, the giant red sea urchin, on its population biology, Ph.D. thesis, Univ. of British Columbia, Vancouver

Ralston, M. (1985). Derivative-free nonlinear regression. In: Dixon, W. J. (ed.) BMDP Statistical Software Manual. University of California Press, Berkeley, p. 305-314

Richards, F. J. (1959). A flexible growth equation for empirical use. J. exp. Bot. 10:290-300

Ricker, W. E. (1973). Linear regression in fishery research. J Fish. Res. Bd Can. 30:409-434

Ricker, W. E. (1975). Computation and interpretation of biological statistics of fish populations. Bull. Fish. Res. Bd Can. 191. 1-382

Rowley, R. J. (1989). Settlement and recruitment of sea

This article was submitted to the editor urchins (Strongylocentrotus spp.) in a sea-urchin barren ground and a kelp bed: are populations regulated by settlement or post-settlement processes? Mar. Biol. 100. $485-494$

Rowley, R. J. (1990). Newly settled sea urchins in a kelp bed and urchin barren ground: a comparison of growth and mortality. Mar. Ecol. Prog. Ser. 62: 229-240

Russell, M. P. (1987). Life history traits and resource allocation in the purple sea urchin, Sirongylocentrotus purpuratus (Stimpson). J. exp. mar. Biol. Ecol. 108: 199-216

Sainsbury, K. J. (1982a). Population dynamics and fishery management of the paua, Haliotis iris. 1. Population structure, growth, reproduction, and mortality. N.Z. J. mar. Freshwat. Res. 16: 147-161

Sainsbury, K. J. (1982b). Population dynamics and fishery management of the paua, Haliotis iris. II. Dynamics and management as examined using a size class population model. N.Z. J. mar. Freshwat. Res. 16: 147-161

Schnute, J T., Richards, L. J., Cass, A. J. (1989). Fish survival and recruitment: investigations based on a size-structured model. Can. J. Fish. Aquat. Sci. 46: 743-769

Schroeter, S. C. (1978). Experimental studies of competition as a factor affecting the distribution and abundance of purple sea urchins, Strongylocentrotus purpuratus (Stimpson). Ph.D. thesis, Univ. Calif. Santa Barbara

Sims, S. E. (1985). Selected computer programs in FORTRAN for fish stock assessment. FAO Fish. tech. Pap. 259: 1-183

Swan, E. F. (1961).Some observations on the growth rate of sea urchins in the genus Strongylocentrotus. Biol. Bull. mar. biol. Lab., Woods Hole 120: 420-427

Tegner, M. (1980). Multispecies considerations of resource management in southern California kelp forests. In: Proceedings of the workshop on the relationship between sea urchin grazing and commercial plant/animal harvesting. Tech. Rep. Fish. Aquat. Sci, Can. 954: 125-143

Tegner, M. (1989). The feasibility of enhancing red sea urchin, Strongylocentrotus franciscanus, stocks in California: an analysis of the options. Mar Fish. Rev. 51: $1-22$

Tegner, M. J., Levin, L. A. (1983). Spiny lobsters and sea urchins: analysis of a predator-prey interaction. J. exp. mar. Biol. Ecol. 73: 125-150

Van Sickle, J. (1977). Mortality rates from size distributions. The application of a conservation law. Oecologia 27: $311-318$

Vedder, J. G., Norris, R. M. (1963). Geology of San Nicolas Island. U.S. Geol. Survey Prof. Pap. 369: 1-65

Wilkinson, L. (1987). SYSTAT The system for statistics. SYSTAT, Inc., Evanston, IL

Manuscript first received: July 1, 1991

Revised version accepted: February 4, 1992 